\title{
Electromyographic recording of the jaw reflex in multiple sclerosis
}

\author{
C. J. GOODWILL ${ }^{1}$ AND L. O'TUAMA \\ From the Departments of Physical Medicine and Neurology, University of Michigan Medical Center, \\ Ann Arbor, Michigan, U.S.A.
}

The clinical value of the jaw reflex is well recognized in the detection of upper motor neurone disease. This sign was first described in 1886 (de Watteville, 1886) and has also been called the 'temporomasseter reflex', 'mandibular reflex', and 'jaw jerk', although Wartenberg (1945) felt that 'jaw reflex' was the appropriate term.

Interruption of the reflex arc is less easily recognized clinically. Thus, the reflex may be reduced in normal subjects and, although the reflex arc is predominantly unilateral and suggested by experimental evidence to be monosynaptic (Corbin and Harrison, 1940; Szentágothai, 1948; McIntyre, 1951; Hugelin and Bonvallet, 1956; McIntyre and Robinson, 1959), it can rarely be lateralized by clinical testing. Mild to moderate wasting or weakness of the jaw muscles is also difficult to assess, especially when bilateral or when malocclusion is present. Therefore, although involvement of the sensory division of the fifth cranial nerve may be detectable clinically, a lesion of the reflex arc or motor division may not be apparent.

Electromyographic recording of the jaw reflex has been used to detect abnormality of the fifth nerve which may not be evident clinically, this method also allowing comparison between the response on each side to a single mechanical stimulus.

The association of trigeminal neuralgia with multiple sclerosis has been known since 1905 (Berger, 1905; Adson, 1926; Parker, 1928). Recent papers suggest that 1 to $2 \%$ of patients with trigeminal neuralgia later develop multiple sclerosis (Müller, 1949; Peet and Schneider, 1952; Dereux, 1952; Ruge, Brochner, and Davis, 1958; Rushton and Olafson, 1965) and that a similar percentage of patients with multiple sclerosis give a history of facial pain indistinguishable from trigeminal neuralgia except that it is more often bilateral. For this reason it appeared probable that some patients with multiple sclerosis, even without clinical indication of fifth

'Present address: Department of Physical Medicine. King's College Hospital, Denmark Hill, London S.E.5. nerve involvement now or in the past, might have abnormality of the fifth cranial nerve.

METHOD

A consecutive unselected series of 32 patients referred to $\overrightarrow{\vec{\omega}}$ the University of Michigan Medical Center with multiple sclerosis was studied. Each patient was examined by one of us (L.O'T), particular note being made of any clinical evidence of fifth nerve abnormality, then the jaw reflex $\omega$ was recorded by the other (C.J.G.) without prior know-? ledge of the clinical findings. The jaw reflex was elicitedd by a tap with a reflex hammer on the midpoint of the patient's chin, the hammer triggering the sweep on which the two electromyographic tracings were displayed. TR ${ }_{-}^{-}$ recordings were made simultaneously from each side $\Phi$ with surface electrodes over each masseter muscle. The mean normal latency as previously reported (Goodw⿳⺈, 1968) was 8.4 msec on each side with a standard deviatien of $1.0 \mathrm{msec}$ and a range of 6.0 to $10.5 \mathrm{msec}$. In that stu通 $\overrightarrow{0}$ the reflex was found to be present bilaterally in each normal subject and the difference in latency between the two sides was not more than $2 \mathrm{msec}$, in 82 out of the $86 \%$

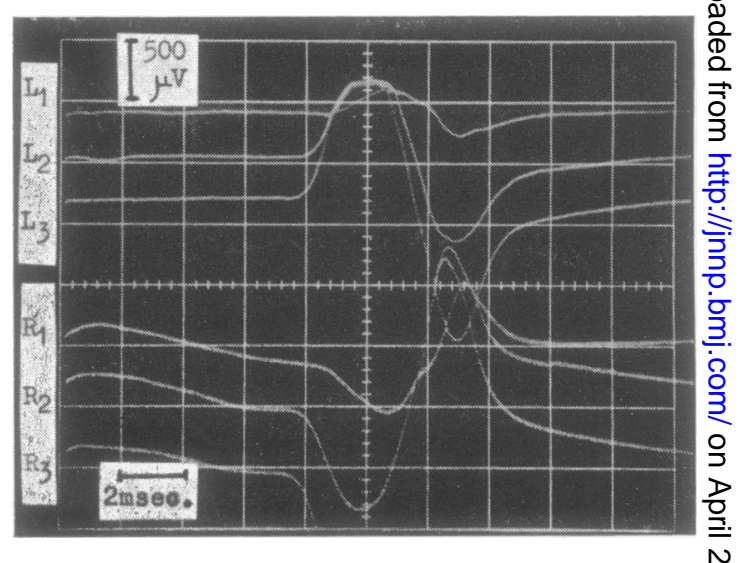

FiG. 1. Normal jaw reflex, three successive responses. This also shows the small decrease in latency on both sidest with increasing strength of the tap on the chin (1 to 3). 
subjects being $1.0 \mathrm{msec}$ or less. The recordings in both that study and this were read to the nearest $0.5 \mathrm{msec}$ (Fig. 1).

Amplitude and duration of response were also measured but gave no additional information in this series and so are not reported.

\section{RESULTS}

Twelve of the 32 patients $(38 \%)$ with multiple sclerosis showed an abnormality, this being a delay or absence of the jaw reflex on one or both sides (Fig. 2) as detailed in Table I. The abnormalities

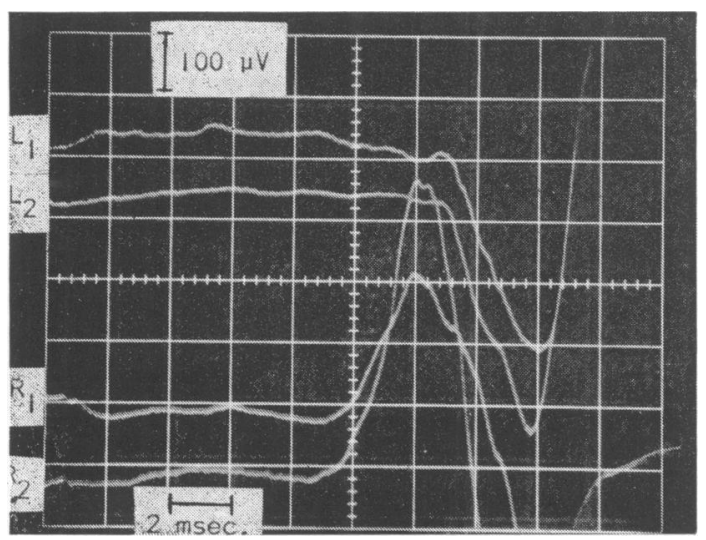

FIG. 2. Abnormal jaw reflex in woman of 46 with multiple sclerosis. Latency left $13.0 \mathrm{msec}$. Right $9.0 \mathrm{msec}$.

were equally distributed between the two sides. Table II shows the mean age and duration of multiple sclerosis compared with the presence or

TABLE I

ABNORMAL REFLEX IN 12 PATIENTS

\begin{tabular}{lcccc}
\hline & Left & Right & Bilateral & Total \\
\hline Delay & 5 & 2 & 0 & 7 \\
Absence & 1 & 3 & 3 & 7 \\
\hline
\end{tabular}

Two patients showed delay on one side and no response on the other.

TABLE II

AGE AND DURATION OF ILLNESS OF PATIENTS WITH MULTIPLE SCLEROSIS

\begin{tabular}{|c|c|c|c|c|c|c|c|}
\hline \multirow[b]{2}{*}{ Jaw reflex } & \multicolumn{4}{|c|}{ Ages (yr) } & \multicolumn{3}{|c|}{$\begin{array}{l}\text { Duration of multiple } \\
\text { sclerosis }(y r)\end{array}$} \\
\hline & No. & Mean & $(S . D)$. & Range & Mean & (S.D.) & Range \\
\hline $\begin{array}{l}\text { Abnormal } \\
\text { Normal }\end{array}$ & $\begin{array}{l}12 \\
20\end{array}$ & $\begin{array}{l}33 \cdot 1 \\
41 \cdot 0\end{array}$ & $\begin{array}{l} \pm 8 \cdot 4 \\
\pm 12 \cdot 8\end{array}$ & $\begin{array}{l}21-48 \\
19-58\end{array}$ & $\begin{array}{l}5 \cdot 2 \\
4 \cdot 7\end{array}$ & $\begin{array}{l} \pm 3 \cdot 2 \\
\pm 2 \cdot 7\end{array}$ & $\begin{array}{l}3-12 \\
1-10\end{array}$ \\
\hline Total & 32 & 38.0 & & $19-58$ & 4.9 & & $1-12$ \\
\hline
\end{tabular}

absence of an abnormal reflex, there being no significant correlation with either of these two factors. However, it is interesting to note the lower mean age in the abnormal group.

The clinical history was compared with the jaw reflex findings (see Addendum) and again there was no correlation between the occurrence of an abnormal reflex and a particular clinical finding on history or examination, and no increased incidence of abnormality with a history of cranial nerve involvement. At the time of this examination no patients had evidence of fifth nerve abnormality and in none was there a history of facial pain. In each patient in whom an abnormal reflex was found electromyography of each masseter was carried out; in no case was there any evidence of denervation. One patient with multiple sclerosis and diabetes mellitus had normal findings on peripheral nerve conduction studies, which together with the absence of clinical history or sign of peripheral neuropathy makes this a very improbable cause of the abnormal jaw reflex.

Figure 3 shows a graph of the findings in all the patients, the darkened area being that of \pm 2 standard deviations from the normal mean of 8.4 msec. Each of those showing a delayed reflex on one side also showed a marked increase in the difference between the two sides above the upper limit of normal of 2 msec.

Case 25 was of particular interest because at the first examination the reflex was unobtainable on the right and of prolonged latency $(11.0 \mathrm{msec})$ on the left, but on the repeat examination three months later the reflex was found to be present and of normal latency on each side, though this was not accompanied by clinical remission of the spastic paraplegia which was her major neurological problem. In two other patients with an abnormal jaw reflex, repeat examination showed no changes.

\section{DISCUSSION}

The results show that electromyographic recording of the jaw reflex can detect abnormality of the fifth cranial nerve when none is detectable clinically. But abnormal clinical findings such as diminished sensation or an absent corneal reflex can occur with a normal jaw reflex, as seen in another patient not included here who had intracranial secondaries from carcinoma of bronchus. This may well be because of the different pathways involved.

Sensation and the afferent side of the corneal reflex are carried in the sensory root of the fifth nerve. This arrangement is in contrast with that of the jaw reflex, whose afferent and efferent sides are both contained in the motor root. The afferent path- 


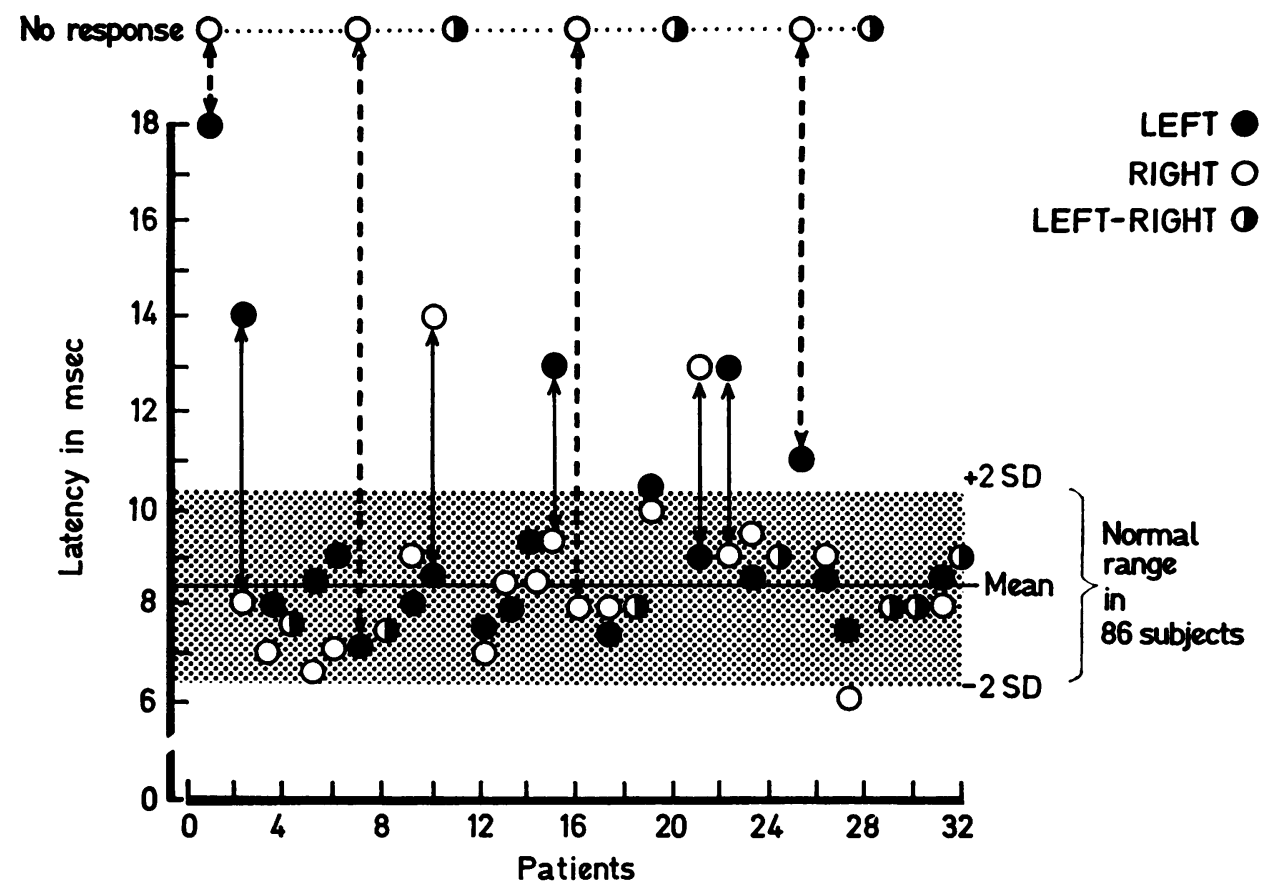

FIG. 3. Normal range of latency of jaw reflex compared with findings in 32 patients with multiple sclerosis.

way of this stretch reflex originates in the muscle spindles of the masticatory muscles, the afferent fibres enter the brain stem in the motor root of the fifth cranial nerve and go to the large, unipolar cells of the mesencephalic trigeminal nucleus. These fibres are distinct from those arising in the Golgi tendon organs, which travel with the sensory root (Szentágothai, 1948; McIntyre and Robinson, 1959).

Abnormality of the jaw reflex was detected in 12 of the 32 patients with multiple sclerosis examined, there being no correlation between this and the duration of the disease or the age of the patient. In no patient was there clinical evidence of fifth nerve involvement, and no patient gave a history of facial pain. One patient, Case 25, showed return of the reflex on examination four months after the initial testing, although this was not accompanied by clinical improvement. In two further patients repeat examination still showed the same abnormality.

Multiple sclerosis is a disease almost exclusively of the central nervous system. The rarity with which it affects the peripheral nervous system was noted by McAlpine, Compston, and Lumsden (1955), who found only two definite reports in the literature describing apparent involvement at this level. Also, in the present series, every patient with an electrically abnormal jaw reflex had a normal electromyogra角光 of the masseter muscles. These considerations mat $\vec{\bullet}$ peripheral neuropathy a most improbable cause of our findings. The exact site of the lesion responsible for these findings awaits pathological detection, but it is suggested that this probably involves the reflex arc at some point between the mesencephalic and motor nuclei of the trigeminal nerve. Figure 4 shows a hemisection of the pons taken from another patient with multiple sclerosis showing an area of demyelina- $\overline{\bar{a}}$ tion in this region. It is suggested that such a lesion $\exists$ could cause the abnormalities that have been discussed.

It may be impossible to confirm the early diagnosis of multiple sclerosis because of lack of dissemination of the lesions in space or time, and objective evidence $\dot{\sigma}$ of a lesion outside the area of clinical involvement might help to support the diagnosis. However, we $ᄋ$ do not know how early in the disease the jaw reflex may show abnormality as the mean duration of the 은 disease in our patients was 4.9 years, and in only one was it less than three years. This technique could be especially useful in patients whose main neuro- $\bar{N}$ logical difficulty was optic neuropathy, or spastic $\sigma$ paraplegia with no signs involving the cranial nerves $N$ -particularly in this last group where the findings 


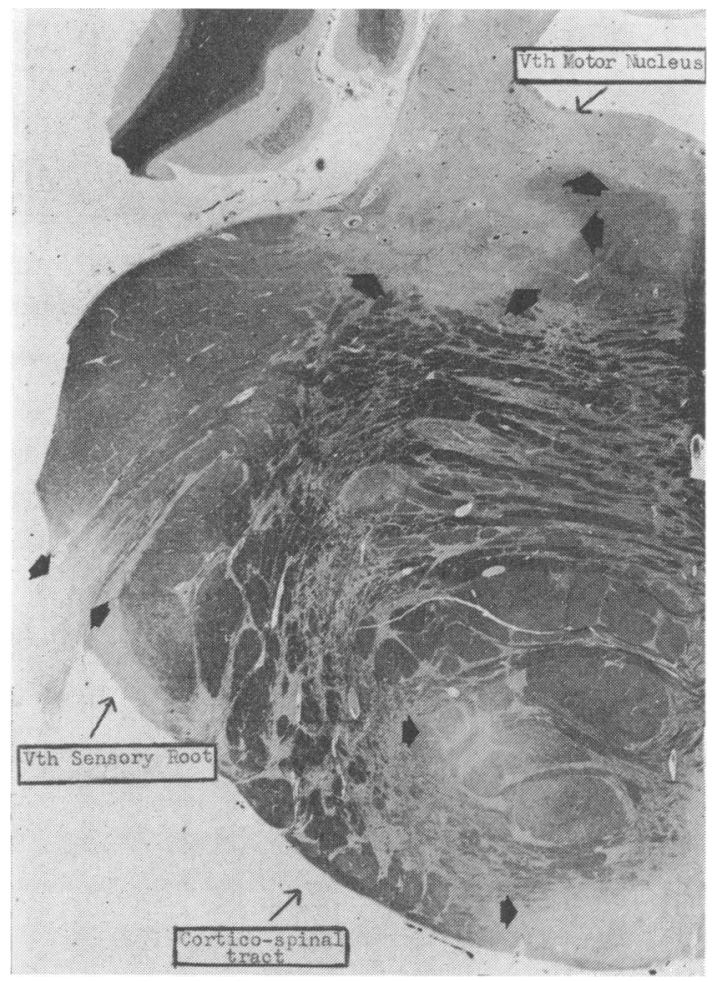

FIG. 4. Necropsy material from case of multiple sclerosis. Hemisection through the tegmentum of the pons at the level of the sensory root of the trigeminal nerve, showing demyelination of the sensory root and root entry zone, and involving also the cells of the motor nucleus of trigeminal. Lesions in this latter distribution may be reflected by the reflex abnormalities described. (An incidental finding is demyelination of the descending corticospinal tract.)

of an abnormality above the level of the cervical cord would be strong evidence against a tumour or other lesion in that region.

It is planned to extend this investigation further, both to allow more prolonged serial study of patients with multiple sclerosis and also to study the jaw reflex in patients with structural lesions affecting the fifth cranial nerve. Studies have begun and suggest that in these cases also this test may show abnormality. Abnormality of the jaw reflex in mesencephalic lesions has also been documented by Hufschmidt and Spuler (1962).

\section{SUMMARY}

Electromyographic recording of the jaw reflex has shown absence or increased latency on one or both sides in 12 of an unselected series of 32 patients with multiple sclerosis. In none of these was there any evidence of lower motor neurone fifth cranial nerve involvement on clinical examination. Suggestions are made as to the probable site of the lesion causing this finding and its value in diagnosis.

It is planned to extend this investigation and to study the jaw reflex in other lesions of the fifth cranial nerve.

We wish to thank Dr. R. N. DeJong, Dr. K. R. Magee, and Dr. H. H. Itabashi, for much valuable advice. We thank Dr. Itabashi for his assistance in obtaining the brain-stem section. This work was in part supported by a grant from the Kenny-Michigan Rehabilitation Foundation.

\section{REFERENCES}

Adson, A. W. (1926). The diagnosis and surgical management of trigeminal neuralgia. Ann. Otol. (St. Louis), 35, 601-625.

Berger, A. (1905). Eine Statistik ueber 206 Faelle von Multipler Sklerose. Jb. Psychiat. Neurol., 25, 178.

Corbin, K. B., and Harrison, F. (1940). Function of mesencephalic root of the fifth cranial nerve. $J$. Neurophysiol., 3, 423-435.

Dereux, J. (1952). Nevralgie faciale et sclérose en plaques. Bull. Acad. nat. Méd. (Paris), 136, 42-43.

Goodwill, C. J. (1968). The normal jaw reflex: measurement of the action potential in the masseter muscles. Ann. phys. Med., 9, 183-188.

Hufschmidt, H. J., and Spuler, H. (1962). Mono and polysynaptic reflexes of the trigeminal muscles in human beings. $J$. Neurol. Neurosurg. Psychiat., 25, 332-335.

Hugelin, A., and Bonvallet, M. (1956). Étude électrophysiologique d'un réflexe monosynaptique trigéminal. C.R. Soc. Biol. (Paris), 150, 2067-2071.

McAlpine, D., Compston, N., and Lumsden, C. (1955). Multiple Sclerosis, pp. 234-236. Livingstone, Edinburgh and London.

McIntyre, A. K. (1951). Afferent limb of the myotatic reflex arc. Nature (Lond.), 168, 168-169.

- - and Robinson, R. G. (1959). Pathway for the jaw-jerk in man Brain, 82, 468-474.

Müller, R. (1949). Studies on disseminated sclerosis, with special reference to symptomatology, course and prognosis. Acta med. scand., 222, (Suppl.), 1-214.

Parker, H. L. (1928). Trigeminal neuralgic pain associated with multiple sclerosis. Brain, 51, 46-62.

Peet, M. M., and Schneider, R. C. (1952). Trigeminal neuralgia : a review of 689 cases with a follow-up study on $65 \%$ of the group. J. Neurosurg., 9, 367-377.

Ruge, D., Brochner, R., and Davis, L. (1958). A study of the treatment of 637 patients with trigeminal neuralgia. J. Neurosurg., 15 528-536.

Rushton, J. G., and Olafson, R. A. (1965). Trigeminal neuralgia associated with multiple sclerosis. Arch. Neurol. (Chic.), 13, 383386.

Szentágothai, J. (1948). Anatomical considerations of monosynaptic reflex arcs. J. Neurophysiol., 11, 445-454.

Wartenberg, R. (1945). The Examination of Reflexes: A Simplification. Yearbook Publishers, Chicago.

de Watteville, A. (1886). A note on the jaw-jerk, or masseteric tendon reaction, in health and disease. Brain, 8, 518-519. 


\begin{tabular}{|c|c|c|c|c|c|c|c|}
\hline \multirow{2}{*}{$\begin{array}{l}\text { Case } \\
\text { No. }\end{array}$} & \multirow[t]{2}{*}{ Age } & \multirow[t]{2}{*}{$\operatorname{Sex}$} & \multirow{2}{*}{$\begin{array}{l}\text { Duration } \\
(y r)\end{array}$} & \multicolumn{3}{|c|}{ Jaw reflex latency } & \multirow[t]{2}{*}{ Clinical summary } \\
\hline & & & & $L$ & $\boldsymbol{R}$ & $L-R$ & \\
\hline 1 & 21 & $\mathbf{F}$ & 3 & $18 \cdot 0$ & Abs & 一 & $\begin{array}{l}\text { Left optic neuropathy } 3 \mathrm{yr} \text { before admission, with remission, followed by spastic } \\
\text { paraparesis. Also diabetes mellitus }\end{array}$ \\
\hline 2 & 33 & $\mathbf{M}$ & 3 & $14 \cdot 0$ & $8 \cdot 0$ & $6 \cdot 0$ & $\begin{array}{l}\text { Spastic paraparesis } 3 \text { yr before admission, with remission. Later developed cerebellaf } \\
\text { ataxia }\end{array}$ \\
\hline 3 & 45 & $\mathbf{M}$ & 5 & $8 \cdot 0$ & $7 \cdot 0$ & $1 \cdot 0$ & $\begin{array}{l}\text { Chronic spastic paraparesis, with periods of exacerbation and remission. Uninhibite } \\
\text { neurogenic bladder }\end{array}$ \\
\hline 4 & 50 & $\mathbf{F}$ & 5 & $7 \cdot 5$ & $7 \cdot 5$ & 0 & $\begin{array}{l}\text { Left retrobulbar neuropathy } 5 \mathrm{yr} \text { before admission, with remission. Later had } \\
\text { posterolateral sclerosis syndrome, with partial remission of the spastic component }\end{array}$ \\
\hline 5 & 21 & $\mathbf{F}$ & 4 & 8.5 & 6.5 & $2 \cdot 0$ & Right optic neuropathy with remission, followed by cerebellar ataxia, truncal mainl \\
\hline 6 & 32 & $\mathbf{F}$ & 10 & $9 \cdot 0$ & $7 \cdot 0$ & $2 \cdot 0$ & $\begin{array}{l}\text { Right retrobulbar neuropathy at onset, with remission, followed by slow development } \\
\text { of spastic tetraparesis (on ACTH) }\end{array}$ \\
\hline 7 & 32 & $\mathbf{F}$ & 10 & $7 \cdot 0$ & Abs & - & Right retrobulbar neuropathy $10 \mathrm{yr}$ previously, followed by mild spastic paraparesi \\
\hline 8 & 47 & $\mathbf{F}$ & 10 & $7 \cdot 5$ & $7 \cdot 5$ & $\mathbf{0}$ & Chronic, severe, spastic paraplegia. Normal CSF and myelogram \\
\hline 9 & 25 & $\mathbf{F}$ & 3 & $8 \cdot 0$ & $9 \cdot 0$ & $-1 \cdot 0$ & $\begin{array}{l}\text { Right retrobulbar neuropathy with remission, followed by right } 6 \text { th nerve palsy, with } \\
\text { remission. Also cerebellar ataxia, mild }\end{array}$ \\
\hline 10 & 25 & $\mathbf{F}$ & 3 & $8 \cdot 5$ & $14 \cdot 0$ & $-5 \cdot 5$ & $\begin{array}{l}\text { Cerebellar ataxia, dissociated nystagmus and spasticity of lower limbs. Course } \\
\text { exacerbation and remission }\end{array}$ \\
\hline 11 & 21 & $\mathbf{M}$ & 3 & Abs & Abs & - & $\begin{array}{l}\text { Exacerbations ( } 3 \text { ) and remissions of severe spastic paraparesis. Also cerebellar ataxia } \\
\text { and posterior column involvement in lower extremities. Negative myelogram }\end{array}$ \\
\hline 12 & 42 & $\mathbf{M}$ & 4 & $7 \cdot 5$ & $7 \cdot 0$ & 0.5 & Chronic spastic paraplegia. No evidence of mass lesion \\
\hline 13 & 52 & $\mathbf{M}$ & 9 & $8 \cdot 0$ & $8 \cdot 5$ & -0.5 & Chronic spastic paraplegia. Myelogram: No evidence of mass lesion \\
\hline 14 & 49 & $\mathbf{F}$ & 3 & $9 \cdot 5$ & $8 \cdot 5$ & $1 \cdot 0$ & $\begin{array}{l}\text { Episode of severe truncal ataxia, followed by mild spastic paraparesis. Myelog } \\
\text { normal }\end{array}$ \\
\hline 15 & 46 & $\mathbf{F}$ & 12 & $13 \cdot 0$ & $9 \cdot 5$ & 3.5 & Episode of retrobulbar neuropathy. Severe spastic paraplegia. Cerebellar ataxia \\
\hline 16 & 48 & $\mathbf{F}$ & 6 & Abs & $8 \cdot 0$ & - & Chronic paraplegia (intense lower limb spasticity). Normal myelogram \\
\hline 17 & 29 & $\mathbf{F}$ & $1 \frac{1}{2}$ & $7 \cdot 5$ & $8 \cdot 0$ & -0.5 & $\begin{array}{l}\text { Right optic neuropathy } 1 \frac{1}{2} \text { yr previously, with remission. Recurrence eight wh } \\
\text { before admission with dissociated nystagmus and right nuclear facial palsy }\end{array}$ \\
\hline 18 & 58 & $\mathbf{M}$ & 10 & $8 \cdot 0$ & $8 \cdot 0$ & $\mathbf{0}$ & Chronic spastic paraplegia, without myelographic evidence of mass lesion \\
\hline 19 & 30 & $\mathbf{F}$ & 3 & $10 \cdot 5$ & $10 \cdot 0$ & 0.5 & Mild spastic paraparesis, without myelographic abnormality \\
\hline 20 & 35 & $\mathbf{F}$ & 3 & Abs & Abs & 一 & $\begin{array}{l}\text { Spastic paraparesis with remission. Later had diplopia, and was found to have } \\
\text { internuclear ophthalmoplegia }\end{array}$ \\
\hline 21 & 33 & $\mathbf{F}$ & 3 & $9 \cdot 0$ & $13 \cdot 0$ & $-4 \cdot 0$ & Severe cerebellar ataxia, mainly truncal. No cause found on investigation \\
\hline 22 & 42 & $\mathbf{M}$ & 3 & $13 \cdot 0$ & $9 \cdot 0$ & $4 \cdot 0$ & $\begin{array}{l}\text { Incapacitating cerebellar vermis syndrome 'dentato-rubro-thalamic' type tremor. } \\
\text { evidence of structural cause }\end{array}$ \\
\hline 23 & 57 & $\mathbf{F}$ & 3 & $8 \cdot 5$ & $9 \cdot 5$ & $-1 \cdot 0$ & Spastic paraparesis. Negative myelogram \\
\hline 24 & 51 & $\mathbf{F}$ & 6 & $9 \cdot 0$ & $9 \cdot 0$ & 0 & Moderate spastic paraparesis, with negative myelography \\
\hline 25 & 32 & $\mathbf{F}$ & 3 & $11 \cdot 0$ & Abs & 一 & Spastic paraplegia. Negative myelography ${ }^{1}$ \\
\hline 26 & 19 & $\mathbf{F}$ & 3 & $8 \cdot 5$ & $9 \cdot 0$ & $-0 \cdot 5$ & $\begin{array}{l}\text { Recurrent episodes of spastic paraparesis, with some posterior column and cerebello } \\
\text { signs in lower limbs }\end{array}$ \\
\hline 27 & 29 & $\mathbf{M}$ & 3 & $7 \cdot 5$ & $6 \cdot 0$ & $1 \cdot 5$ & Spastic paraparesis, with moderate cerebellar ataxia \\
\hline 28 & 29 & $\mathbf{F}$ & 10 & Abs & Abs & 一 & Spastic paraparesis (negative myelogram) \\
\hline 29 & 54 & $\mathbf{F}$ & 3 & $8 \cdot 0$ & $8 \cdot 0$ & 0 & Mild spastic paraparesis (negative myelogram) \\
\hline 30 & 51 & $\mathbf{F}$ & 3 & $8 \cdot 0$ & $8 \cdot 0$ & $\mathbf{0}$ & Mild spastic paraparesis (negative myelogram) \\
\hline 31 & 54 & $\mathbf{F}$ & 3 & $8 \cdot 5$ & $8 \cdot 0$ & 0.5 & $\begin{array}{l}\text { Right spastic hemiparesis, with mainly truncal ataxia, proprioception impaired } \\
\text { lower limbs }\end{array}$ \\
\hline 32 & 25 & $\mathbf{F}$ & 3 & $9 \cdot 0$ & $9 \cdot 0$ & $\mathbf{0}$ & Truncal ataxia, scanning speech and hyperreflexia \\
\hline
\end{tabular}

'Bilaterally normal latencies and duration at re-examination four months later, despite absence of clinical change. 